\title{
Climbing-Related Injury Among Adults in the United States: 5-Year Analysis of the National Emergency Department Sample
}

\author{
Joseph D. Forrester, MD, MSc; Kenneth Tran, MD; Lakshika Tennakoon, MPhil, MSc; \\ Kristan Staudenmayer, MD, MS \\ From the Divisions of General Surgery (Drs Forrester and Staudenmayer, and Ms. Tennakoon); and Vascular Surgery (Dr Tran), \\ Department of Surgery, Stanford University, Stanford, CA.
}

\begin{abstract}
Introduction-Rock climbing and mountaineering are popular outdoor recreational activities. More recently, indoor climbing has become popular, which has increased the number of persons at risk for climbing-related injuries. The purpose of this study was to assess the morbidity, mortality, and healthcare cost due to climbing-related injury among persons presenting to US emergency departments (ED).

Methods-We performed a retrospective analysis of the 2010 to 2014 National Emergency Department Sample database, a nationally representative sample of all visits to US EDs. Rock climbing, mountain climbing, and wall climbing injuries were identified using International Classification of Diseases, Ninth Revision, Clinical Modification codes (E004.0). Outcomes evaluated included morbidity, mortality, inpatient admission, and costs. Adjusted analyses accounting for survey methodology were performed.

Results-A weighted-estimate 15,116 adult ED visits were associated with climbing-related injury. Patient age was $32.8 \pm 14.7$ (mean \pm SD) $(95 \%$ CI: $32.1-33.5)$ y, and $62 \%$ of patients were male. The majority of the injuries occurred in the Western census region $(9593 ; 63 \%)$. Less than $1 \%$ of all climbing-related visits resulted in death. Only of injury severity score $>15$ was associated with death $(P=0.005)$. A total of $1610(11 \%)$ of patients were admitted as inpatients. Accounting for ED and inpatient costs, climbing-related injuries cost the US healthcare system approximately $\$ 102(95 \% \mathrm{CI}$ : \$75-130) million USD for the 5-y period, averaging \$20 \pm 9.5 million USD per $y$.

Conclusions-Most persons with climbing-related injuries presenting to EDs do not require inpatient admission. Although death is rare among patients with climbing-related injuries, the costs of injuries in survivors remain high.
\end{abstract}

Keywords: trauma, climbing-related-injury, death, mountaineering, climbing, rock climbing

\section{Background}

Over the past decade, indoor wall climbing, outdoor rock climbing, and mountaineering have become increasingly popular sports. ${ }^{1,2}$ The Outdoor Industry Association estimated in 2016 there were over 6 million active participants in indoor and outdoor climbing, accounting for $2 \%$

This work was presented as an oral abstract presentation at the Wilderness Medical Society (WMS) Summer Conference and Annual Meeting, Sunday, August 5, 2018, Midway, UT.

Corresponding author: Joseph D. Forrester, 300 Pasteur Drive, Stanford, CA 94305; e-mail: jdf1 @ stanford.edu.

Submitted for publication February 2018.

Accepted for publication May 2018. of the US population over 6 years of age. ${ }^{3}$ More than 430 gyms are now open in North America, with an average $8 \%$ growth in the number of gyms opened per year over the last $5 \mathrm{y} .{ }^{4}$ Increased exposure to indoor climbing facilities may act as a "gateway," secondarily increasing the number of people who may go on to rock climb outdoors or mountaineer. ${ }^{5,6}$

Indoor and outdoor rock climbing and mountaineering can result in injury (collectively considered climbing-related injuries), which ranges from the inherent risk of falling and hitting objects or the ground, to stress-related climbing injuries due to the unique forces placed on the musculoskeletal system. ${ }^{1,7}$ Yet despite growing popularity of rock climbing and mountaineering, the healthcare and financial burden of 
these climbing-related injuries remains poorly understood. The purpose of this study was to analyze the burden of climbing-related injury to the US healthcare system by assessing the morbidity, mortality, frequency of inpatient admission, and healthcare cost due to injured climbers presenting to the emergency department (ED).

\section{Methods}

We used data from the Agency for Healthcare and Quality, Healthcare Cost and Utilization Project's National Emergency Department Sample (NEDS) from 2010 to 2014 to describe the epidemiology of climbing-related injury among persons presenting to EDs in the United States. ${ }^{8}$ NEDS is the largest all-payer ED database in the United States, capturing both ED encounters that result in discharge or transfer and ED encounters that result in admission. Publically available, NEDS is constructed from the healthcare cost and utilization project state emergency department databases and the state inpatient databases. When analyzed, NEDS is weighted to provide national estimates of ED care; the NEDS stratified sample of US hospital-based EDs represents approximately $20 \%$ of all US ED visits. The number of hospitals included in the sample ranged from 945 to 961 and reported 149,704,876 (667,095,064 after weighting) ED encounters over the 5-y time period. We included all adult ED encounters with the diagnosis code corresponding to rock climbing, mountain climbing, or wall climbing injury (International Classification of Disease, Ninth Revision, Clinical Modification [ICD-9CM] E004.0). An extended definition for an adult was used (age $>16$ y) to reflect the demographics of those recreationally participating in mountaineering, rock climbing, or wall climbing.

Rock climbing, mountaineering, and wall climbing injuries were collectively analyzed as "climbing-related injuries" because no further specificity was available in the NEDS dataset. Variables assessed included age, sex, US census region, payer status, income quartile, anatomic location of injury, injury severity score (ISS), length of stay, and discharge destination. Costs were derived from reported charges converted to costs using healthcare cost and utilization project cost-to-charge ratios. Injury characteristics were further evaluated using the Stata-based ICD Programs for Injury Categorization module. ${ }^{9}$ ISS is a validated anatomical scoring system that provides a measure of the overall severity of injury for patients with multiple injuries. ${ }^{10,11}$ The 2010 to 2014 time period was chosen because both databases were available at the time of analysis and had consistent coding to enable combinatorial analysis.

Outcomes of interest included morbidity, mortality, inpatient admission, and cost. All statistical analyses used the NEDS sampling strata and discharge weights to produce nationally weighted patient-level estimates and
95\% confidence intervals that account for clustering of patients among hospitals. Weighted values are reported unless otherwise specified. Data are presented as mean \pm $\mathrm{SD}$; calculated weighted means are reported with $95 \%$ CI according to survey statistical methodology. Univariate and multivariate analyses were performed. The a priori $P$ value considered significant was $P<0.05$. Stata 12.0 (StataCorp, College Station, TX) was used for all statistical analyses. The study was classified exempt following institutional review board review because it contained no identifiable data.

\section{Results}

A total of 3275 unweighted adult ED visits was associated with a climbing-related injury, with $655 \pm 55$ (591-722) climbing-related injuries per year. After weighting, the estimate was a total of 15,116 ED visits over the observed time period, with $3023 \pm 149$ climbing-related injuries presenting to an ED annually. This corresponds to 23 climbing-related injuries per 1 million patient visits (Table 1). Patient age was $32.8 \pm 14.7$ (95\% CI: $32.1-33.5)$ years, and $62 \%$ of patients were male. The majority of the injuries were in the West census region (9593; 63\%), 2177 (14\%) in the South, $1855(12 \%)$ in the Northeast, and $1492(10 \%)$ in the Midwest. Most $(n=9591 ; 63 \%)$ patients had private insurance. Patients with an income in the top quartile of those living in their zip code comprised the majority $(n=5733 ; 38 \%)$ of the injured, although patients from all 4 income quartiles were represented. Among patient presenting to the ED, $9034(60 \%)$ had multiple body regions injured and 4893 $(32 \%)$ had isolated extremity injuries.

Less than $1 \%$ of all climbing-related visits resulted in death. The only variable associated with death on univariate analysis was ISS $>15(P<0.001)$, and this stayed significant on multivariate analysis $(P=0.005)$. The vast majority $(13,213 ; 87 \%)$ of patients were discharged home from the ED; only $1610(11 \%)$ were admitted as inpatients. Mean inpatient length of stay was 3.6 (95\% CI: 3.0-4.1) days. Factors associated with inpatient admission included male sex $(P=0.01)$, hospital region $(P=0.014)$, private insurance $(P<0.001)$, quartile of household income $(P=0.024)$, injury location $(P<0.001)$, and ISS $(P<0.001)$. On multivariate analysis only injury burden and ISS $>15$ were associated with inpatient admission $(P<0.001)$.

The weighted-estimate mean ED cost per each presentation for a climbing-related injury was $\$ 2280$ (95\% CI $\$ 2079-2480)$ USD over the years included in the study. If admitted, the weighted-estimate mean cost was $\$ 64,929$ (95\% CI: $\$ 49,244-80,615)$ USD over the same time period. On average accounting for both ED and inpatient costs, climbing-related injuries among persons presenting 
Table 1. Epidemiology of patients presenting to the emergency department with climbing-related injuries—United States, 20102014

\begin{tabular}{|c|c|c|c|c|}
\hline Variable & $\begin{array}{l}\text { Unweighted E0040 - } \\
\text { mountain climbing, } \\
\text { rock climbing, wall } \\
\text { climbing (\%) ED } \\
\text { data }\end{array}$ & $\begin{array}{l}\text { Unweighted E0040 - } \\
\text { mountain climbing, } \\
\text { rock climbing, wall } \\
\text { climbing (\%) inpatient } \\
\text { data }\end{array}$ & $\begin{array}{l}\text { Weighted E0040- } \\
\text { mountain climbing, } \\
\text { rock climbing, wall } \\
\text { climbing (\%) ED } \\
\text { data }\end{array}$ & $\begin{array}{l}\text { Weighted E0040-- } \\
\text { mountain climbing, } \\
\text { rock climbing, wall } \\
\text { climbing (\%) inpatient } \\
\text { data }\end{array}$ \\
\hline Number & 3275 & 331 & 15,116 & 1610 \\
\hline \multicolumn{5}{|l|}{ Age, y } \\
\hline$<18$ & $181(6)$ & $15(5)$ & $836(6)$ & $68(4)$ \\
\hline $18-44$ & $2401(73)$ & $233(70)$ & $11,137(74)$ & $1164(72)$ \\
\hline $45-64$ & $550(17)$ & $70(21)$ & $2491(16)$ & $318(20)$ \\
\hline $65-74$ & $95(3)$ & $9(3)$ & $435(3)$ & $39(2)$ \\
\hline $75-84$ & $39(1)$ & $3(1)$ & $177(1)$ & $14(1)$ \\
\hline$\geq 85$ & $9(0)$ & $1(0)$ & $39(0)$ & $6(0)$ \\
\hline Male sex & $2020(62)$ & $224(68)$ & $9387(62)$ & $1083(67)$ \\
\hline \multicolumn{5}{|l|}{ Region } \\
\hline Northeast & $383(12)$ & $34(10)$ & $1855(12)$ & $163(10)$ \\
\hline Midwest & $285(9)$ & $39(12)$ & $1492(10)$ & $208(13)$ \\
\hline South & $511(16)$ & $36(11)$ & 2177 (14) & $162(10)$ \\
\hline West & $2096(64)$ & $222(67)$ & $9593(63)$ & 1077 (67) \\
\hline \multicolumn{5}{|l|}{ Payment data } \\
\hline Medicare & $163(5)$ & $13(4)$ & $756(5)$ & $60(4)$ \\
\hline Medicaid & $306(9)$ & $27(8)$ & $1359(9)$ & $115(7)$ \\
\hline Private insurance & $2053(63)$ & $220(66)$ & $9591(63)$ & $1091(68)$ \\
\hline Self-pay & $487(15)$ & $30(9)$ & $2276(15)$ & $160(10)$ \\
\hline No charge & $23(1)$ & $6(2)$ & $110(1)$ & $26(2)$ \\
\hline Other & $229(7)$ & $35(11)$ & $1025(7)$ & $158(10)$ \\
\hline \multicolumn{5}{|l|}{$\begin{array}{l}\text { Household income compared } \\
\text { with patient's zip code }\end{array}$} \\
\hline $0-25$ th & $458(15)$ & $51(16)$ & $2,198(15)$ & $247(15)$ \\
\hline 26th-50th & $661(21)$ & $47(15)$ & $3233(21)$ & $237(15)$ \\
\hline $51 \mathrm{st}-75 \mathrm{th}$ & $824(26)$ & $95(30)$ & $3951(26)$ & $487(30)$ \\
\hline 76th-100th & $1191(38)$ & $122(39)$ & $5733(38)$ & $639(40)$ \\
\hline \multicolumn{5}{|l|}{ Anatomic site of injury } \\
\hline Isolated head/neck & $156(5)$ & $9(3)$ & $689(5)$ & $43(3)$ \\
\hline Isolated face & $9(0)$ & $2(1)$ & $39(0)$ & $10(1)$ \\
\hline Isolated chest & $37(1)$ & $11(3)$ & $193(1)$ & $64(4)$ \\
\hline Isolated abdomen & $44(1)$ & $17(5)$ & $233(2)$ & $105(7)$ \\
\hline Isolated extremity & $1056(32)$ & $156(47)$ & $4893(32)$ & $777(48)$ \\
\hline Isolated external & $6(0)$ & $0(0)$ & $32(0)$ & $0(0)$ \\
\hline Multiple body regions & $1967(60)$ & $136(41)$ & $9034(60)$ & $610(38)$ \\
\hline Injury severity score $>15$ & $46(1)$ & $36(11)$ & $242(2)$ & $162(10)$ \\
\hline $\begin{array}{l}\text { Length of stay (mean } \pm \text { SD } \\
{[95 \% \text { CI }] \text { ) days }{ }^{\mathrm{a}}}\end{array}$ & N/A & $3.7 \pm 4.4[3.2-4.2]$ & N/A & $3.6[3.0-4.1]^{\mathrm{a}}$ \\
\hline \multicolumn{5}{|l|}{ Discharge destination } \\
\hline Died in ED & $2(0)$ & $0(0)$ & $9(0)$ & $0(0)$ \\
\hline Home & $2880(88)$ & $263(79)$ & $13,213(87)$ & $1294(80)$ \\
\hline Admitted as inpatient & $331(11)$ & N/A & $1610(11)$ & N/A \\
\hline Transfer to another facility & $41(1)$ & $14(4)$ & $192(1)$ & $59(4)$ \\
\hline Skilled nursing facility & $12(0)$ & $34(10)$ & $51(0)$ & $157(10)$ \\
\hline Home health & $2(0)$ & $17(5)$ & $9(0)$ & $89(6)$ \\
\hline Against medical advice & $6(0)$ & $2(1)$ & $26(0)$ & $7(0)$ \\
\hline Unknown & $1(0)$ & $1(0)$ & $6(0)$ & $4(0)$ \\
\hline
\end{tabular}


Table 1 (Continued)

\begin{tabular}{|c|c|c|c|c|}
\hline Variable & $\begin{array}{l}\text { Unweighted E0040 - } \\
\text { mountain climbing, } \\
\text { rock climbing, wall } \\
\text { climbing (\%) ED } \\
\text { data }\end{array}$ & $\begin{array}{l}\text { Unweighted E0040 - } \\
\text { mountain climbing, } \\
\text { rock climbing, wall } \\
\text { climbing (\%) inpatient } \\
\text { data }\end{array}$ & $\begin{array}{l}\text { Weighted E0040 - } \\
\text { mountain climbing, } \\
\text { rock climbing, wall } \\
\text { climbing (\%) ED } \\
\text { data }\end{array}$ & $\begin{array}{l}\text { Weighted E0040 - } \\
\text { mountain climbing, } \\
\text { rock climbing, wall } \\
\text { climbing (\%) inpatient } \\
\text { data }\end{array}$ \\
\hline $\begin{array}{l}\text { Individual patient ED cost } \\
\qquad(\text { mean } \pm \mathrm{SD}[95 \% \mathrm{CI}]) \mathrm{USD}^{\mathrm{a}}\end{array}$ & $\begin{array}{l}\$ 2319 \pm 3326 \\
{[\$ 2167-2469]}\end{array}$ & $\begin{array}{r}\$ 2271 \pm \$ 1558 \\
{[\$ 2039-2503]}\end{array}$ & $\begin{array}{c}\$ 2280 \\
{[\$ 2079-2480]^{\mathrm{a}}}\end{array}$ & $\begin{array}{c}\$ 2368 \\
{[\$ 1973-2763]^{\mathrm{a}}}\end{array}$ \\
\hline $\begin{array}{l}\text { Individual patient cost for hospi- } \\
\text { talization (mean } \pm \text { SD [range]) } \\
\text { USD }\end{array}$ & N/A & $\begin{array}{c}\$ 71,130 \pm \$ 115,956 \\
{[\$ 58,397-83,863]}\end{array}$ & N/A & $\begin{array}{c}\$ 64,929[\$ 49,244- \\
80,615]^{\mathrm{a}}\end{array}$ \\
\hline Total ED cost $[95 \% \mathrm{CI}]$ USD & $\begin{array}{l}\$ 4,307,831 \\
{[\$ 4,026,625-} \\
4,589,036]\end{array}$ & $\begin{array}{c}\$ 399,710[\$ 358,929- \\
440,490]\end{array}$ & $\begin{array}{l}\$ 20,000,000 \\
{[\$ 16,200,000-} \\
23,900,000]\end{array}$ & $\begin{array}{l}\$ 2,032,600 \\
{[\$ 1,406,912-} \\
2,658,289]\end{array}$ \\
\hline $\begin{array}{l}\text { Total hospitalization cost } \\
{[95 \% \mathrm{CI}] \text { USD }}\end{array}$ & N/A & $\begin{array}{l}\$ 22,800,000 \\
{[\$ 18,700,000-} \\
26,900,000]\end{array}$ & N/A & $\begin{array}{c}\$ 102,000,000 \\
{[\$ 75,300,000-} \\
128,000,000]\end{array}$ \\
\hline
\end{tabular}

ED, emergency department; N/A, not applicable; USD, United States dollars.

${ }^{\text {a }}$ Standard deviations not reportable for weighted-estimate means.

to the ED cost the US healthcare system approximately $\$ 102$ (95\% CI: \$75-130) million USD for the 5-y period, averaging \$20 \pm 9.5 million USD per year (Figure 1).

\section{Discussion}

Participation in both indoor and outdoor rock climbing has increased considerably over the past decade in the United States. ${ }^{3}$ The frequency of climbing-related injury appears to have paralleled this increase in popularity. ${ }^{2}$ Although numerous studies describe a range of expected injuries, ${ }^{12-18}$ there are no modern assessments of climbing-related injury in the United States based on large nationally representative healthcare databases. A prior study that investigated climbing-related injuries from 1990 to 2007 used the national electronic injury surveillance system, which comprises a small stratified probability sample of 100 US emergency departments. ${ }^{2}$ Although an important first step in describing the epidemiology of national climbing-related injury, this study's survey sample was limited. Regardless of this limitation, the authors reported an average estimated 2237 annual climbing-related ED presentations and noted the frequency of admission increased 63\% from 1995 to $2007 .^{2}$ Overall, we found an average annual rate of 3023 persons who experienced climbing-related injury, which was an increase of $34 \%$ from the national electronic injury surveillance system 1995 to 2007 study. ${ }^{2}$ The rate of hospital admission $(\sim 11 \%)$ remained consistent between the 2 studies. $^{2}$

Hospital mortality was extremely rare after climbingrelated injuries. Less than $1 \%$ of all patients who survived to the hospital died, and none of these deaths occurred as an inpatient. When our data is compared with available prehospital climbing-related fatality data, our findings suggest that death associated with climbing-related injuries often happens at the site of injury or less commonly during prehospital transport. Between 2010 and 2014, the Center for Disease Control and Prevention's wide-ranging online data for epidemiologic research mortality data identified 360 deaths recorded as "falls from cliff" (ICD-10 code W15). ${ }^{19}$ Although the specific ICD-10 code W15 does not provide the same level of specificity of activity performed as the ICD-9-CM E004.0, it is a useful approximation for estimating underlying causes of mortality. Similarly, Accidents in North American Mountaineering is a self-reported registry of climbing accidents managed by the American Alpine Club. This registry reported 142 recreational climbingrelated deaths reported over the same time period. ${ }^{20}$ Assuming the ED deaths identified through our analysis of NEDS were captured among these fatalities identified in Center for Disease Control and Prevention's wide-ranging online data for epidemiologic research and accidents in north american mountaineering, 94 to $97 \%$ of climbing fatalities in the United States happen in the prehospital setting and likely before arrival of prehospital transport or rescue. This proposition is supported by historic data from Yosemite National Park; among the 13 patients who died in the 220 climbing accidents evaluated, all were dead before arrival of rescue services and prehospital transport. ${ }^{16}$ An important implication of this finding pertains to rescuers. Although rapid transport of survivors to definitive care is important, this should not occur at the cost of rescuer safety.

To our knowledge, this is the first study to report the costs associated with hospital visits for climbing-related injuries, and these costs are considerable. Over \$20 million USD per year is estimated to have been spent 


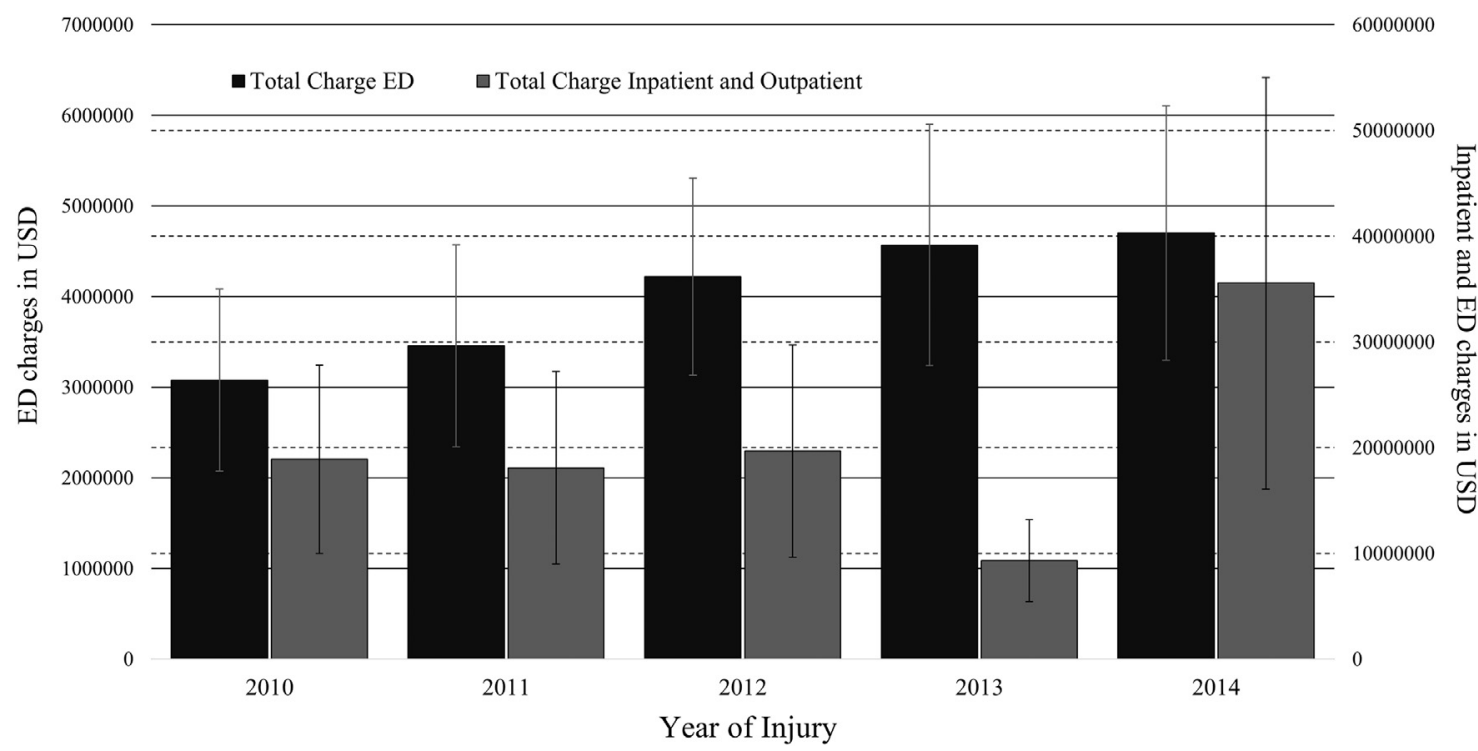

Figure 1. Weighted total cost per year in US dollars for emergency department and inpatient admissions due to climbing injury-United States, 2010-2014.

on climbing-related injury among patients who present to EDs. For patients who are admitted, the financial impact even greater-the initial inpatient hospital costs is nearly $\$ 65,000$. These values represent an underestimate of the true financial burden because they reflect only costs associated with acute inpatient visits and do not take into account the cost of rehabilitation, physician charges, outpatient referrals to specialty providers, outpatient surgery, or lost wages. For those climbers with injuries sufficiently severe to warrant admission, the high hospital costs and likely resultant disability may have a significant and longterm financial impact on the young patients who sustain these injuries.

Most patients sustained injuries to multiple body regions $(60 \%)$. Isolated extremity injuries were second most common $(32 \%)$, with relatively few patients experiencing isolated chest or abdominal trauma $(2 \%)$. These findings are comparable to prior studies that reported that fractures and sprains/strains accounted for a large proportion of injury. ${ }^{2,16}$ These more often occurred in the lower extremities. ${ }^{2,16}$ In contrast, a 2015 single-center study from Europe characterized acute $(n=380 ;$ ED) and nonacute $(n=359$; outpatient visit) climbing-related injuries and found most injuries occurred to the upper extremities $(91 \%))^{21}$ This difference can be explained given that the population of climbers included in the 2015 study was evaluated in both an elective orthopedic practice as well in the hospital setting, which would bias the sample toward less acute injuries.

Unfortunately, little is known about the long-term morbidity associated with climbing-related injury. Compared with other sports injuries, the $11 \%$ hospital admission rate among injured climbers is high, ${ }^{22}$ suggesting that associated morbidity of injury may also be high. Additionally, almost one-fifth of injured climbers who were admitted to the hospital required a skilled nursing facility or home health service after hospital discharge, suggesting a more debilitating burden of injury. This finding supports survey results published in 2017 that found nearly $45 \%$ of injured climbers reported some type of long-term disability. ${ }^{23}$ Given that climbers are a physically active cohort of hospitalized patients based on the circumstances during which they were injured, prolonged physical disability may be associated with significant psychological stress not quantified in our analysis. ${ }^{24}$

This study has several limitations. Recreational climbing occurs along a spectrum, from relatively low-risk indoor rock climbing to inherently higher risk activities such as technical mountaineering. ${ }^{1}$ The complexity of this objective risk is not characterized in the NEDS dataset. However, we believe that our study represents an important step forward in defining the healthcare burden and cost of climbing-related injury in the United States. Second, there may be misclassification bias associated with utilizing ICD-9 codes; the validity of the codes depends on the quality of coders at each participating institution. Third, as no universally accepted definitions exist for rock climbing, wall climbing, and mountaineering, ${ }^{1}$ reporting of activities not typically associated with recreational climbing may have been included inadvertently by coders. This could falsely increase the number of recreational climbing-related injury and could vary by hospital region. The ability to assess for potential variation in coding practices by region for climbing-related injury is outside the scope of this manuscript. Fourth, NEDS reports event-level data but does not 
have unique identifiers for any given individual; an individual responsible for multiple visits over the course of the year would be counted as multiple individuals. This may lead to overestimation of the number of injured persons. Fifth, our study only captures patients presenting to EDs and does not account for deaths that occur at the time of injury or during prehospital transport. Thus, by definition the overall cost of climbing-related injuries to the US healthcare system based on our data alone is an underestimate of the true total cost. Finally, although NEDS is the most comprehensive survey of EDs in the United States, it may not accurately capture EDs in close proximity to popular climbing areas. This could lead to overestimation or underestimation of climbing-related injury.

\section{Conclusions}

As indoor rock climbing, outdoor rock climbing, and mountaineering have become more popular recreational activities, an increase in climbing-related injuries has been seen in US EDs. The costs of these injuries are similarly increasing. Most deaths from climbing-related injury appear to occur at the scene or during prehospital transport; the mortality rate after arrival to an ED is surprisingly low. Hospital admission is high when compared with other sports-related injuries at approximately 1 in 10 ED visits. Given the growing popularity of these sports a better understanding of the risks leading to climbingrelated injuries is important to mitigate the human and financial costs associated with these activities.

Author Contribution: Data collection (LT); data analysis (JDF, KT, LT, KS); data interpretation (JDF, KT, KS); writing (JDF, KT, KS).

Financial/Material Support: None.

Disclosure: None.

\section{References}

1. Schoffl V, Morrison A, Schoffl I, Kupper T. The epidemiology of injury in mountaineering, rock and ice climbing. Med Sport Sci. 2012;58:17-43.

2. Nelson NG, McKenzie LB. Rock climbing injuries treated in emergency departments in the US, 1990-2007. Am J Prev Med. 2009;37(3):195-200.

3. The Outdoor Foundation. Outdoor Participation Report. Washington DC: The Outdoor Foundation; 2016. Available at: https://outdoorindustry.org/wp-content/uploads/2016/ 09/2016-Outdoor-Recreation-Participation-Report_FI-

NAL.pdf. Accessed March 25, 2018.

4. Climbing Business Journal. Gyms and Trends of 2016; 2017. Available at: http://www.climbingbusinessjournal. com/gyms-and-trends-of-2016/. Accessed January 25, 2018.

5. Long J. Gym Climb! Evergreen, CO: Chockstone Press; 1994.

6. Rapelje BW. Rock Climbing Sub-worlds: A Segmentation Study [Master's thesis]. College Station, TX: Office of
Graduate Studies of Texas A\&M University. Texas A\&M University; 2004. Accessed July 18, 2018.

7. Jones G, Asghar A, Llewellyn DJ. The epidemiology of rock-climbing injuries. $\mathrm{Br} J$ Sports Med. 2008;42 (9):773-8.

8. HCUP Nationwide Emergency Department Sample (NEDS). Healthcare Cost and Utilization Project (HCUP). 2010-2014 Agency for Healthcare Research and Quality, Rockville, MD. Available at: www.hcup-us.ahrq.gov/nedso verview.jsp. Accessed July 18, 2018.

9. Clark DE, Osler TM, Hahn DR. ICD Programs for Injury Categorization (ICDPIC), Version 3.0. 2010. http://ideas.repec. org/c/boc/bocode/s457028.html. Accessed July 18, 2018.

10. Evaluating trauma care: the TRISS method. Trauma Score and the Injury Severity Score. J Trauma. 27;(4):1987 370-8.

11. Glance LG, Osler TM, Mukamel DB, Meredith W, Dick AW. Expert consensus vs empirical estimation of injury severity: effect on quality measurement in trauma. Arch Surg. 2009;144(4):326-32

12. Smith LO. Alpine climbing: injuries and illness. Phys Med Rehabil Clin N Am. 2006;17(3):633-44.

13. Gerdes EM, Hafner JW, Aldag JC. Injury patterns and safety practices of rock climbers. J Trauma. 2006;61 (6): $1517-25$

14. Wright DM, Royle TJ, Marshall T. Indoor rock climbing: who gets injured? Br J Sports Med. 2001;35(3):181-5.

15. Paige TE, Fiore DC, Houston JD. Injury in traditional and sport rock climbing. Wilderness Environ Med. 1998;9(1):2-7.

16. Bowie WS, Hunt TK, Allen Jr HA. Rock-climbing injuries in Yosemite National Park. West J Med. 1988;149(2):172-7.

17. Rooks MD, Johnston 3rd RB, Ensor CD, McIntosh B, James S. Injury patterns in recreational rock climbers. Am J Sports Med. 1995;23(6):683-5.

18. Addiss DG, Baker SP. Mountaineering and rock-climbing injuries in US national parks. Ann Emerg Med. 1989;18 (9):975-9.

19. Centers for Disease Control and Prevention. Underlying Cause of Death, 1999-2015. CDC Wide-ranging Online Data for Epidemiologic Research. Available at: https://won der.cdc.gov. Accessed March 25, 2018.

20. Williamson JE, ed. Accidents in North American Mountaineering 2015. Golden, CO: The American Alpine Club; 2015.

21. Schoffl V, Popp D, Kupper T, Schoffl I. Injury trends in rock climbers: evaluation of a case series of 911 injuries between 2009 and 2012. Wilderness Environ Med. 2015;26(1):62-7.

22. Nonfatal sports- and recreation-related injuries treated in emergency departments-United States, July 2000-June 2001. MMWR Morb Mortal Wkly Rep. 2002;51(33):736-40.

23. McDonald JW, Henrie AM, Teramoto M, Medina E, Willick SE. Descriptive epidemiology, medical evaluation, and outcomes of rock climbing injuries. Wilderness Environ Med. 2017;28(3):185-96.

24. Kellezi B, Coupland C, Morriss R, Beckett K, Joseph S, Barnes J, et al. The impact of psychological factors on recovery from injury: a multicentre cohort study. Soc Psychiatry Psychiatr Epidemiol. 2017;52(7):855-66. 